Advances in Geosciences, 7, 73-77, 2006

SRef-ID: $1680-7359 /$ adgeo/2006-7-73

European Geosciences Union

(c) 2006 Author(s). This work is licensed

under a Creative Commons License.

\title{
Heavy rain and strong wind events and cyclones in the Balearics
}

\author{
J. Campins, A. Jansà, and A. Genovés \\ Centro Meteorológico en Illes Balears, Instituto Nacional de Meteorología, Spain
}

Received: 28 October 2005 - Revised: 21 December 2005 - Accepted: 21 December 2005 - Published: 24 January 2006

\begin{abstract}
The relationship between heavy rain (HR) and/or strong wind (SW) events and cyclones is investigated for the Balearic Islands. First, a list of HR and SW events is crossreferenced with an objective cyclone database for a 9-year period (from June 1995 to May 2004). The presence of a cyclone centre close to the Balearics is looked for each event. For HR events in most of the cases a cyclone centre is located in the vicinity. Furthermore, cyclones are located in such a way that allow the supply of warm and wet air to the affected area. But for SW events, although in the majority of cases a cyclone centre is detected, cyclones are located farther than for HR events and their geographical location is more widespread. Afterwards, the three-dimensional structure of cyclones related to HR and/or SW events is studied in detail.
\end{abstract}

\section{Introduction}

The Mediterranean basin is reckoned as a region with a high frequency of cyclones and cyclogeneses (Petterssen, 1956). These cyclones strongly influence the weather and the climate of the Mediterranean as well as their neighbouring regions (Radinovic, 1987). Thus, heavy rain and strong wind (hereafter referred as HR and SW) events are frequently related to cyclones. The relationship between HR and cyclones has been demonstrated for both singular cases (Ramis et al., 1998; Jansà et al., 2000) and from an statistical point of view (Jansà et al., 2001; Romero et al., 1999). This relationship is on the basis of the MEDEX project, which main objective is to increase the knowledge and improve the forecasting of cyclones that produce high impact weather in the Mediterranean (see MEDEX Science Plan Phase 1 at http://medex.inm.uib.es).

The objective of the present work is to investigate the relationship between HR and SW events and the presence of cyclone centres for the Balearic Islands. Thus, as a first approach the simultaneity between the occurrence of HR and SW and the presence of a cyclone centre is studied. But as the presence of cyclone centres in the Western Mediterranean is high, it could be argued that this fact allows a high degree of coincidence. To clarify that, the simultaneity of cyclone centres is also looked for a randomly selected set of events. Finally, HR and SW simultaneous cyclone centres are studied in more detail and also compared with those simultaneous to the random set of events.

\section{Datasets}

\subsection{Heavy rain and strong wind in the Balearics}

As HR and SW data a 9-year period is selected (from June 1995 to May 2004). Data are obtained from 216 pluviometric and 12 wind stations located throughout the Balearic Islands. A certain day D is considered as event if at least one station overcame a certain threshold. For HR, the threshold is $60 \mathrm{~mm}$ in $24 \mathrm{~h}$ and for SW two different thresholds are imposed: for wind gusts $\geq 25 \mathrm{~ms}^{-1}$ or sustained wind $\geq 18 \mathrm{~ms}^{-1}$ ( $\geq 33 \mathrm{~ms}^{-1}$ and $\geq 25 \mathrm{~ms}^{-1}$ for elevated stations). Those thresholds are the same than for the MEDEX database.

For the study period a total of $157 \mathrm{HR}$ and $98 \mathrm{SW}$ events are detected, that is a mean of 17.4 and 10.9 events per year. The seasonal distribution of HR and/or SW events is presented in Table 1. For HR events the well-known autumn maximum (Font, 1983) is found, although in all the other seasons HR events could be also produced. However, SW events dominate in winter, and in to lesser extent in autumn and spring, while in summer no events are produced. Finally, only 16 events of HR and SW (simultaneously) are produced (a mean of 1.8 events per year), most of them in autumn. 
Table 1. Mean number per year of HR, SW and HR-SW events in the Balearic Islands and cyclone centres in the Western Mediterranean for seasons and for the whole year. June 1995 to May 2004.

\begin{tabular}{lccccc}
\hline Event & Winter & Spring & Summer & Autumn & Year \\
\hline HR & 3.3 & 3.0 & 2.5 & 8.6 & 17.4 \\
SW & 5.1 & 2.1 & 0.0 & 3.7 & 10.9 \\
HR-SW & 0.4 & 0.2 & 0.0 & 1.2 & 1.8 \\
Cyclone centres & 320 & 488 & 580 & 371 & 1759 \\
\hline
\end{tabular}

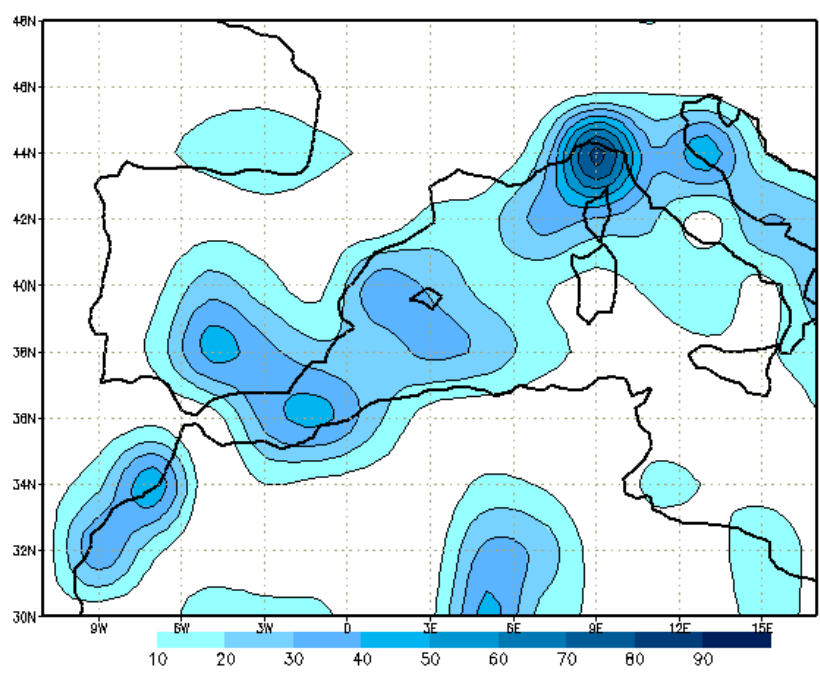

Fig. 1. Mean number of cyclone centres (in $2^{\circ} \times 2^{\circ}$ latitudelongitude boxes) for the Western Mediterranean. June 1995 to May 2004. Contour interval 10 cyclone centres per year.

\subsection{Cyclone centres in the Western Mediterranean}

The cyclone centre dataset is an objective database derived from smoothed analyses at 00:00, 06:00, 12:00 and 18:00 UTC of the High Resolution Limited Area Model from the Instituto Nacional de Meteorología, with an original resolution of $0.5^{\circ}$ latitude-longitude. The study area comprises from $29^{\circ} \mathrm{N}$ to $49^{\circ} \mathrm{N}$ and $12^{\circ} \mathrm{W}$ to $18^{\circ} \mathrm{E}$, the so-called Western Mediterranean. The same period is selected: from June 1995 to May 2004. Cyclone centres are detected and tracked from mean sea level pressure fields and three-dimensionally characterized by a set of variables. More details about the detection, tracking and three-dimensional characterization algorithms can be found in Picornell et al. (2001) and Campins et al. (2006).

As Fig. 1 shows in the Western Mediterranean cyclone centres locate in preferred regions: the gulf of Genoa, the south-eastern corner of the Iberian peninsula, the Alboran and Balearic Seas and in mainland of North-Africa. But this distribution is seasonal dependant: during summer cyclone centres tend to locate over land and in winter over sea. The seasonal distribution (Table 1) exhibits a maximum in summer, when many shallow and weak thermal lows develop. On
Table 2. Relative frequency (\%) of cyclone centres simultaneous to $\mathrm{HR}$ and RA-CLO datasets located within a certain radius $(\mathrm{km})$ from the Balearic Islands.

\begin{tabular}{lcccccc}
\hline Dataset & $\leq 100$ & $\leq 200$ & $\leq 300$ & $\leq 400$ & $\leq 500$ & $\leq 600$ \\
\hline HR & 14.6 & 37.6 & 56.0 & 70.7 & 80.3 & 86.0 \\
RA-CLO & 6.6 & 18.2 & 28.4 & 37.8 & 46.9 & 56.6 \\
\hline
\end{tabular}

the contrary in winter fewer centres are observed, but those are deep and more intense (Campins et al., 2006).

Both HR and SW events and the cyclone centres datasets are available at the MEDEX web page http://medex.inm.uib. es).

\section{Methodology}

As mentioned, the first objective of the present study is to look for simultaneity between HR or SW events and the presence of a cyclone centre. Initially, for a certain event all the detected cyclone centres are considered. That is, for HR events cyclone centres detected at 06:00, 12:00 and 18:00 UTC of day D and at 00:00 UTC for day D+1 (as the pluviometric day compresses from 07:00 to 07:00 UTC) and for SW events those detected at 00:00, 06:00, 12:00 and 18:00 UTC are took into account. But which of these potential cyclone centres is related in same way to the hazardous event?. Several objective criteria have been used and compared with a subjective inspection. Thus, for HR events the closest centre, located within a radius of $600 \mathrm{~km}$, is considered as the best simultaneous cyclone centre. On the contrary as SW events are mainly related to strong pressure gradients that are spread along large distances, the closest cyclone centre criteria allow many wrong matches. Instead, for SW events the more intense cyclone centre is considered, whatever its proximity.

But as the presence of cyclone centres in the Western Mediterranean (and around the Balearics) is very high (Table 1 and Fig. 1), it could be argued that for almost any event a cyclone centre could be detected. To clarify that the simultaneity of cyclone centres is also looked for a randomly selected set of events. Since when looking for simultaneity two criteria for HR and for SW events are used (the closest and the more intense centres), then both criteria are also used when the randomly selected set of events is cross-referenced with the database of cyclone centres. As a result two datasets of cyclone centres simultaneous to the random one are obtained: one with the closest criterion (so-called RA-CLO) and the other with the more intense one (so-called RA-INT).

Finally, cyclone centres simultaneous to HR and SW events are studied in more detail and compared to each other and with those simultaneous to the random set of events. That comprises their location, thickness and threedimensional structure. 

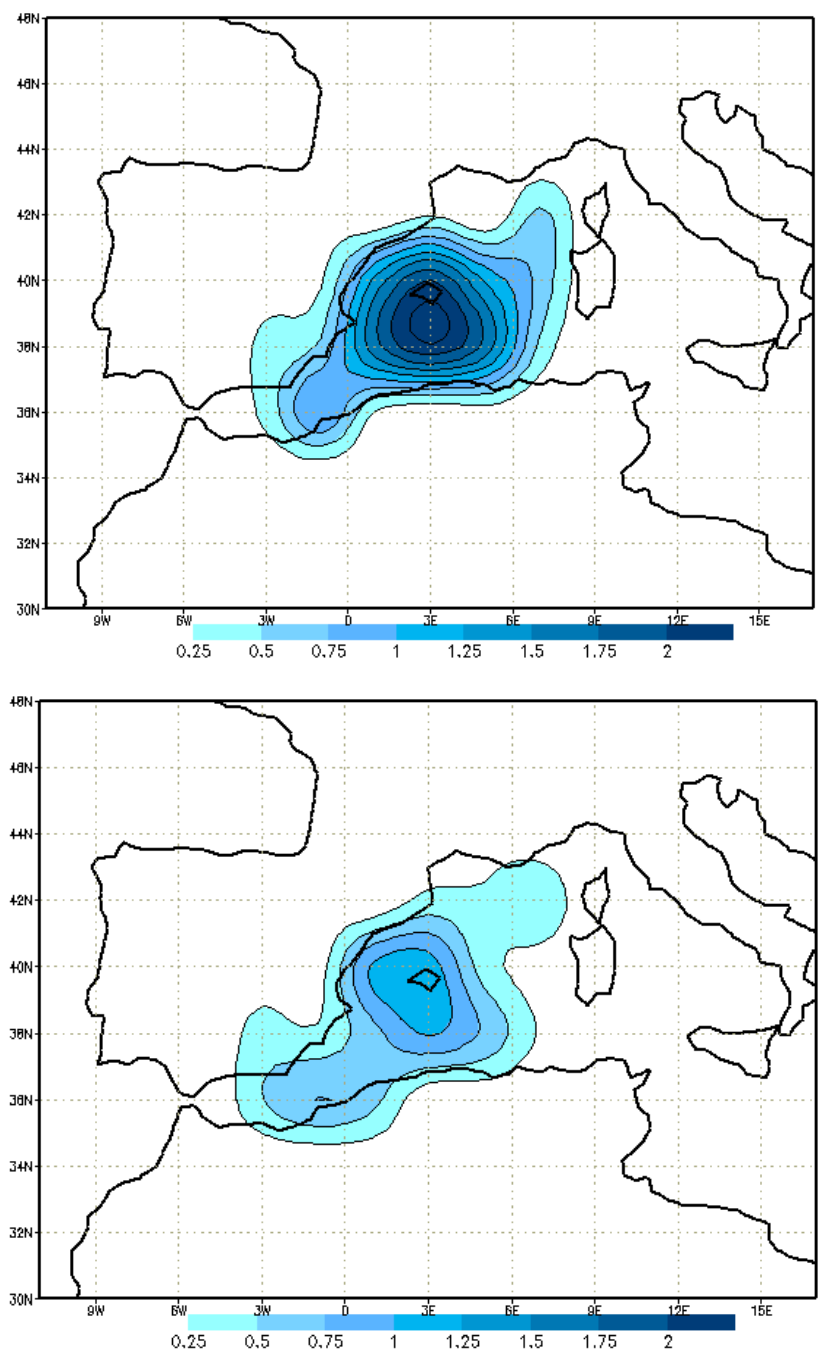

Fig. 2. Mean number of cyclone centres (in $2^{\circ} \times 2^{\circ}$ latitudelongitude boxes) simultaneous to HR events (top) and to RA-CLO dataset (bottom). Contour interval 0.25 cyclone centres per year.

\section{Results}

\subsection{HR events and cyclone centres}

The simultaneity between HR events and the presence of a cyclone centre close to the Balearics is clearly higher than for the random set of events $(86.0 \%$ and $56.6 \%$; see Table 2$)$. Moreover, these cyclone centres are located southwards of the Balearics, although for the RA-CLO dataset the maximum is located further south-westwards of the Balearics and cyclones are more widespread along the Western Mediterranean (Fig. 2).

Furthermore cyclone centres simultaneous to the HR events are deeper than the random ones (Table 4). Mean three-dimensional characteristic of cyclone centres related to HR events are quite similar to the random ones, although some differences can be underlined: they are more intense, specially at low levels, with a stronger cold-core character at
Table 3. Relative frequency (\%) of cyclone centres simultaneous to $\mathrm{SW}$ and RA-INT datasets located within a certain radius $(\mathrm{km})$ from the Balearic Islands.

\begin{tabular}{lccccc}
\hline Dataset & $\leq 300$ & $\leq 600$ & $\leq 900$ & $\leq 1200$ & $\leq 1500$ \\
\hline SW & 15.3 & 33.7 & 53.1 & 83.7 & 98.0 \\
RA-INT & 12.0 & 24.7 & 43.6 & 73.5 & 89.6 \\
\hline
\end{tabular}

Table 4. Frequency (\%) of cyclone centres per thickness for different datasets of events and for the whole study area (Western Mediterranean).

\begin{tabular}{lccc}
\hline Dataset & Shallow & Middle-depth & Deep \\
\hline HR & 36.3 & 5.9 & 57.8 \\
RA-CLO & 62.0 & 7.4 & 30.6 \\
SW & 12.5 & 9.4 & 78.1 \\
RA-INT & 43.8 & 10.7 & 45.5 \\
HR-SW & 0.0 & 18.7 & 81.3 \\
Western Mediterranean & 51.1 & 11.1 & 37.8 \\
\hline
\end{tabular}

medium levels and higher potential instability at the low ones (Table 5).

\subsection{SW events and cyclone centres}

In almost all the SW events and the random set of events a cyclone centre is found, but located farther than for HR events (Table 3) and in different regions (Fig. 3). Thus, for SW events, cyclone centres are located close to the Balearics (over the Islands or eastwards) or far away (in the Adriatic Sea and to a lesser extent in Tyrrhenian Sea). For the randomly selected set of events, cyclone centres are located in the most frequent locations of cyclones (compare Figs. 1 and 3 bottom).

Moreover, most of the cyclone centres related to SW events are deep (78.1\%). Besides, their mean profiles reveal that those centres are more intense and with a higher geostrophic vorticity at all levels than the random ones. Thermal and humidity values are similar, although SW related cyclone centres exhibit lower moist static stability (that is larger potential instability) than the random ones.

Finally, a comparison between HR and SW related cyclone centres can be performed (Tables 4 and 5). As it could be expected, since different criterion was used, SW related cyclone centres are deeper, with a higher geostrophic vorticity and more intense at all levels than the HR related ones. Thermal character at low levels is similar (i.e. warm-core) but cold-core character at medium levels is more stressed for SW ones. Relative humidity and moist static stability are similar. 
Table 5. Mean values of some parameters at low (L) and medium (M) or upper (U) levels of cyclone centres for different datasets of events. $\zeta_{g}$ : geostrophic vorticity $\left(10^{-6} \mathrm{~s}^{-1}\right)$, GC: geostrophic circulation $\left(10^{7} \mathrm{~m}^{2} \mathrm{~s}^{-1}\right)$, R: mean radius $(\mathrm{km}), \Delta \mathrm{T}$ : laplacian of temperature $\left.10^{-6} \mathrm{C} \mathrm{km}^{-2}\right)$, RH: relative humidity (\%), V: mean wind speed $\left(\mathrm{ms}^{-1}\right)$ and $\sigma_{e}$ : moist static stability $\left(10^{-6} \mathrm{C} \mathrm{km}^{-2}\right)$.

\begin{tabular}{lccccccccccccc}
\hline Dataset & $\zeta_{g}$ & $\zeta_{g}$ & $\mathrm{GC}$ & $\mathrm{GC}$ & $\mathrm{R}$ & $\mathrm{R}$ & $\Delta \mathrm{T}$ & $\Delta \mathrm{T}$ & $\mathrm{RH}$ & $\mathrm{RH}$ & $\mathrm{V}$ & $\mathrm{V}$ & $\sigma_{e}$ \\
\hline & $\mathrm{L}$ & $\mathrm{U}$ & $\mathrm{L}$ & $\mathrm{U}$ & $\mathrm{L}$ & $\mathrm{U}$ & $\mathrm{L}$ & $\mathrm{M}$ & $\mathrm{L}$ & $\mathrm{M}$ & $\mathrm{L}$ & $\mathrm{U}$ & $\mathrm{L}$ \\
\hline HR & 60.0 & 122.6 & 3.7 & 12.8 & 436 & 554 & -41.5 & 26.2 & 75 & 62 & 7.5 & 23.4 & -3.8 \\
RA-CLO & 54.2 & 103.4 & 2.9 & 10.5 & 403 & 538 & -46.2 & 17.4 & 66 & 58 & 6.8 & 21.4 & -2.2 \\
SW & 74.7 & 133.1 & 7.0 & 16.0 & 543 & 607 & -41.1 & 18.0 & 75 & 61 & 10.5 & 27.2 & -3.2 \\
RA-INT & 59.1 & 106.8 & 4.2 & 11.6 & 468 & 565 & -47.1 & 14.5 & 66 & 53 & 7.5 & 23.4 & -1.3 \\
HW-SW & 80.4 & 144.1 & 6.4 & 14.8 & 501 & 560 & -39.3 & 23.9 & 78 & 66 & 11.3 & 25.5 & -4.5 \\
\hline
\end{tabular}
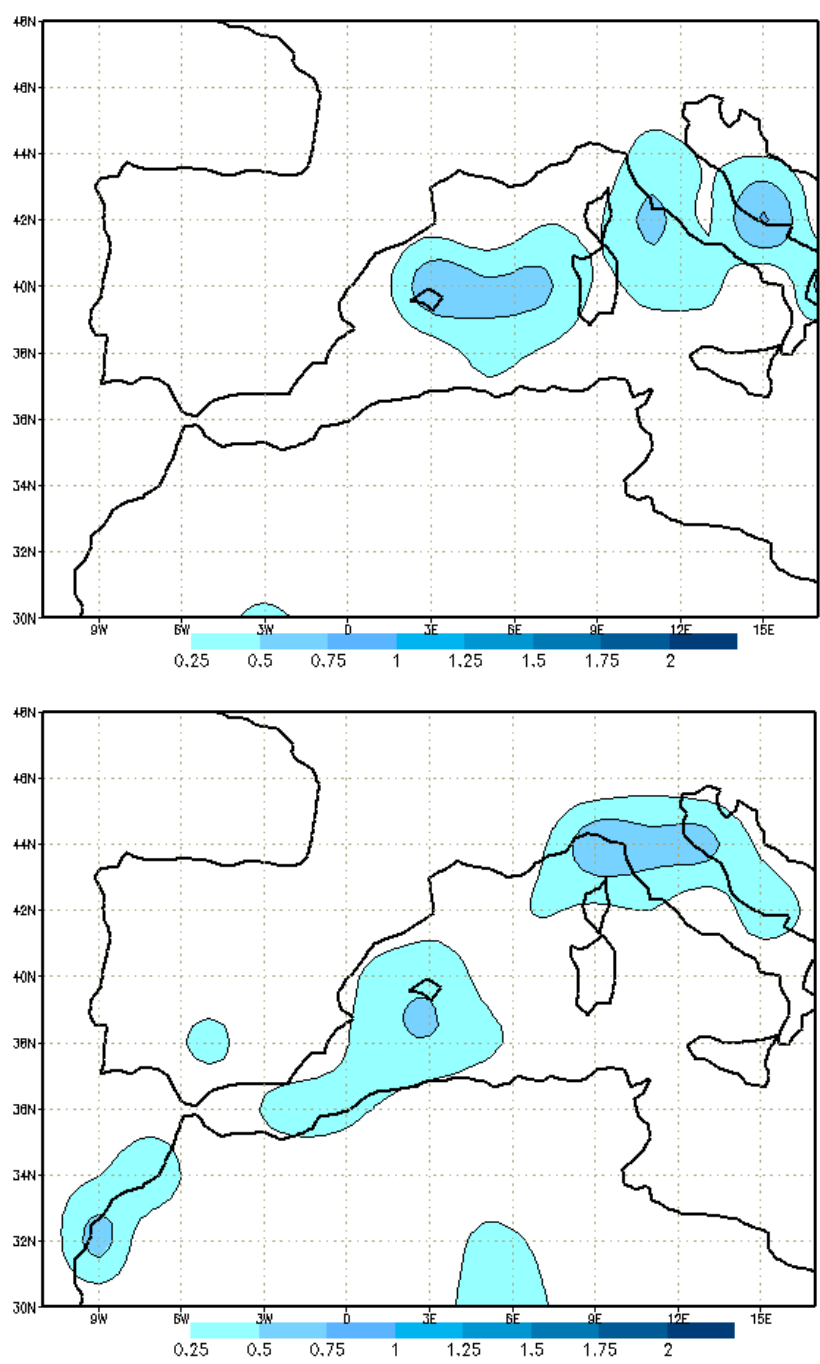

Fig. 3. Mean number of cyclone centres (in $2^{\circ} \times 2^{\circ}$ latitudelongitude boxes) simultaneous to SW events (top) and to RA-INT dataset (bottom). Contour interval 0.25 cyclone centres per year.

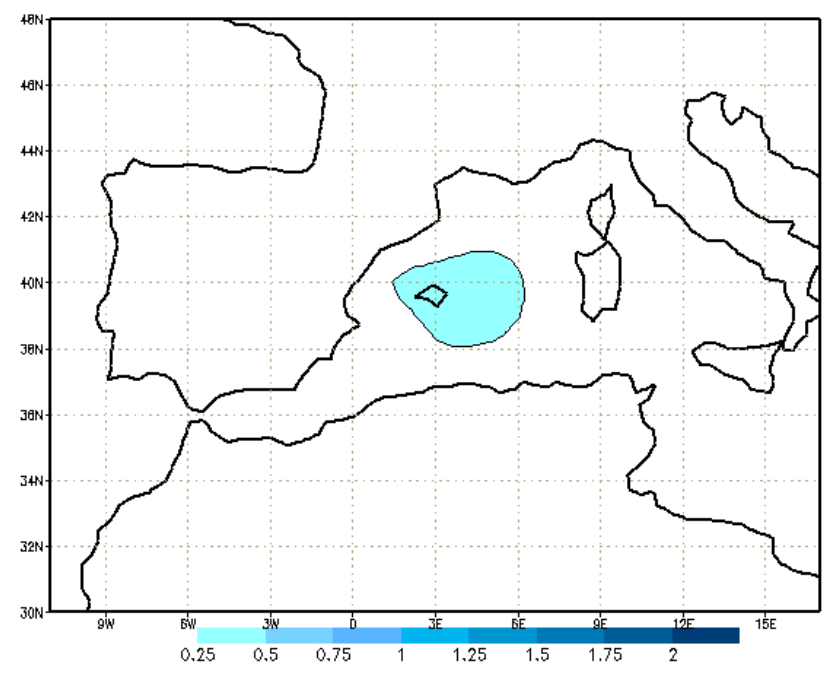

Fig. 4. Mean number of cyclone centres (in $2^{\circ} \times 2^{\circ}$ latitudelongitude boxes) simultaneous to HR and SW events. Contour interval 0.25 cyclone centres per year.

\subsection{HR-SW events and cyclone centres}

Although the HR and SW set of events is very small, some results can be underlined. In all the HR-SW events a cyclone centre is found. Moreover, such cyclone centres locate very close to the Balearics (Fig. 4). These cyclones are well developed lows (most of them are deep, see Table 4), large and very intense at all levels, with a marked cold-core character at medium levels, large values of relative humidity at low and even medium levels and potentially unstable (compare mean values for different datasets in Table 5).

\section{Conclusions}

In most of the HR events a cyclone centre is located close to the Balearics, allowing the supply of warm and wet air. Cyclone centres simultaneous to HR events are deeper, a little more intense, with a larger cold-core character at medium levels and with higher potential instability at low levels than their random counterparts. 
In almost all the SW events a cyclone centre is found, however their distribution is more widespread than for HR events. Cyclone centres simultaneous to SW events are clearly deeper, larger, more intense and with higher potential instability than their random counterparts.

On average cyclone centres simultaneous to $\mathrm{HR}$ and to SW events are also different one to each other. Thus, SW related cyclones are well developed lows, deep and intense. However HR related ones are composed by both shallow and moderate centres as well as deep and intense cyclones.

In all the HR-SW events a cyclone centre locates very close of the Balearics. These cyclone centres are deep, intense and not very large. Besides they exhibit a strong coldcore character at medium levels and high potential instability at low ones.

This is a first attempt to perform a dynamically oriented climatology of cyclones that produce high impact weather in the Mediterranean, one of the objectives of MEDEX project, although such studies has to be enlarged to include other Mediterranean regions.

Edited by: V. Kotroni and K. Lagouvardos Reviewed by: anonymous referee

\section{References}

Campins, J., Jansà, A., and Genovés, A. : Three-dimensional structure of Western Mediterranean cyclones, Int. J. Climatol., accepted, 2006.

Font, I. : Climatología de España y Portugal, Instituto Nacional de Meteorología, Madrid, 1983.

Jansà, A., Genovés, A., and García-Moya, J. A.: Western Mediterranean cyclones and heavy rain. Part I: Numerical experiment concerning the Piedmont flood case, Meteorol. Appl., 7, 323$333,2000$.

Jansà, A., Genovés, A., Picornell, M. A., Campins, J., Riosalido, R., and Carretero, O. : Western Mediterranean cyclones and heavy rain. Part II: Statistical approach, Meteorol. Appl., 8, 43$56,2001$.

Petterssen, S. : Weather and Forecasting Vol. I, McGraw-Hill, New York, 1956.

Picornell, M. A., Jansà, A., Genovés, A., and Campins, J.: Automated database of mesocyclones from HIRLAM(INM)- $0.5^{\circ}$ analyses in the Western Mediterranean, Int. J. Climatol., 21, 335354, 2001.

Radinovic, D.: Mediterranean cyclones and their influence on the weather and the climate, WMO, PSMP Rep. Ser. Num, 24., 1987.

Ramis, C., Romero, R., Homar, V., Alonso, S., and Alarcón, M.: Diagnosis and numerical simulation of a torrential precipitation event in Catalonia (Spain), Meteorol. Atmos. Phys., 69, 1-21, 1998.

Romero, R., Sumner, G., Ramis, C., and Genovés, A.: A classification of the atmospheric circulation patterns producing significant daily rainfall in the Spanish Mediterranean area, Int. J. Climatol., 19, 765-785, 1999. 